\title{
Investigation on the Oxidation and Reduction of Titanium in Molten Salt with the Soluble TiC Anode
}

\author{
SHULAN WANG, CHAOPIN WAN, XUAN LIU, and LI LI
}

To reveal the oxidation process of titanium from TiC anode and the reduction mechanism of titanium ions in molten $\mathrm{NaCl}-\mathrm{KCl}$, the polarization curve of $\mathrm{TiC}$ anode in molten $\mathrm{NaCl}-\mathrm{KCl}$ and cyclic voltammograms of the molten salt after polarization were studied. Investigation on the polarization curve shows that titanium can be oxidized and dissociated from the TiC anode at very low potential. The cyclic voltammograms demonstrated that the reduction reaction of titanium ions in the molten salt is a one-step process. By potentiostatic electrolysis, dendritic titanium is obtained on the steel plate. The work promotes the understanding on the process of electrochemical oxidization/dissociation of titanium from $\mathrm{TiC}$ anode and the reduction mechanism of titanium ions in molten salt.

DOI: $10.1007 / \mathrm{s} 40553-015-0062-9$

(C) ASM International (ASM) and The Minerals, Metals \& Materials Society (TMS) 2015

TITANIUM and its alloys have wide applications in microelectronics, biomaterials, and aerospace because of their excellent physicochemical properties, such as high strength, low density, high temperature stability, and excellent corrosion resistance. ${ }^{[1-3]}$ Tremendous efforts have been made in the past two decades to establish new processing routes to replace the existing Kroll process, ${ }^{[4]}$ which has the disadvantages of high economic input. The novel FFC Cambridge process has been proposed to extract titanium from titanium dioxide, ${ }^{[5-7]}$ and has been extended to extract a wide range of active metals and alloys. ${ }^{[8-14]}$ The FFC Cambridge process has also been used to prepare $\mathrm{Ti}_{2} \mathrm{CO}_{n}$ functional materials for the application of surface decoration. ${ }^{[15]}$ Other titanium extraction methods have also been developed, such as the Ono Suzuki process which combines calcium thermal reduction and an electrolysis process in the same cell ${ }^{[16,17]}$ the direct molten oxide electrolysis at temperatures above the melting point of mixed oxide, ${ }^{[18]}$ and the USTB process ${ }^{[19,20]}$ in which $\mathrm{Ti}_{2} \mathrm{CO}$ as the soluble anode is electrolyzed in the molten salt. In addition, Takeuchi et al. conducted potentiostatic electrolysis in molten $\mathrm{NaCl}-\mathrm{KCl}-\mathrm{TiCl}_{2}-\mathrm{TiCl}_{3}$ using $\mathrm{TiC}$, TiO, and Ti-C-O as anodes. ${ }^{[21,22]}$ In the case of $\mathrm{TiC}$ anode, titanium was extracted at high ratio with low carbon content due to carbon produced in situ in the TiC anode. However, the fundamental investigation of anode dissociation/titanium deposition was not performed and the redox reaction mechanism of the electrolysis is still unknown.

SHULAN WANG, Professor, and CHAOPIN WAN, Graduate Student, are with the Department of Chemistry, School of Science, Northeastern University, Shenyang 110819, China. XUAN LIU, Research Associate, is with the Department of Materials Science and Engineering, Carnegie Mellon University, Pittsburgh, PA 15213. LI LI, Postdoctoral Associate, is with the Department of Materials Science and Engineering, Cornell University, Ithaca, NY 14850.

Contact e-mails: lilicmu@alumni.cmu.edu; lilicmu@gmail.com

Manuscript submitted May 9, 2015.

Article published online November 23, 2015
Understanding the diffusion and reaction behaviors of the active species in electrolytes is very important for achieving high efficiency of electrolysis and revealing corresponding reaction mechanisms of the electrodes. ${ }^{[23-26]}$ For example, the diffusion coefficient of metallic ion $\mathrm{Zn}^{2+}, \mathrm{Pb}^{2+}$, and $\mathrm{Mg}^{2+}$ in molten $\mathrm{KCl}-\mathrm{LiCl}$ has been studied and compared with the result obtained from various electrochemical techniques. ${ }^{[23]}$ The electrochemical behavior of $\mathrm{Fe}^{3+}$ in $\mathrm{CaCl}_{2}-\mathrm{KF}$ has also been studied by cyclic voltammetry/chronopotentiometry and the electrochemical kinetics has been analyzed. ${ }^{[24]}$ Among all molten salt systems, the $\mathrm{NaCl}-\mathrm{KCl}$ mixture has several advantages over the others, such as a high electrical conductivity, a low melting point, absence of moisture absorbance, and low cost. ${ }^{[27]}$ Furthermore, the $\mathrm{NaCl}-\mathrm{KCl}$ mixture has the second widest potential window due to the high decomposition potentials of 3.18 and $3.45 \mathrm{~V}$ at $1073 \mathrm{~K}\left(800^{\circ} \mathrm{C}\right)$, respectively, for $\mathrm{NaCl}$ and $\mathrm{KCl}^{[28]} \mathrm{TiC}$ has the electrical conductivity as high as $4.75 \times 10^{5} \mathrm{~S} \mathrm{~m}^{-1}$ even at room temperature ${ }^{[29]}$ and is considered as one of the best soluble anode candidates.

In the present work, polarization curve of $\mathrm{TiC}$ anode and cyclic voltammograms of molten $\mathrm{NaCl}-\mathrm{KCl}$ and potentiostatic electrolysis were investigated and performed aiming to enhance the understanding on the process of electrochemical oxidation as well as dissociation of titanium from $\mathrm{TiC}$ anode and the reduction mechanism of titanium ions in molten salt by using techniques such as linear sweep voltammetry and cyclic voltammetry. The current study provides the important scientific guidance for the further improvements of titanium processing by molten salt electrolysis.

TiC powder (99 pct, Institute of Non-ferrous Metal, Beijing) and polyethylene glycol ( 1 wt pct used as binder) were mixed and pressed into pellets $(15 \mathrm{~mm}$ in diameter and $3 \mathrm{~mm}$ in thickness). The pellets were then sintered in argon atmosphere at $1223 \mathrm{~K}\left(950{ }^{\circ} \mathrm{C}\right)$ for 4 hours with a heating rate of $5{ }^{\circ} \mathrm{C} \mathrm{min}^{-1}$ and a hole was drilled in the upper side of each pellet. A thin nickel 
wire $(0.2 \mathrm{~mm}$ in diameter) was used to hold the pellets to a molybdenum wire $(1.5 \mathrm{~mm}$ in diameter) as the anode. $\mathrm{NaCl}$ and $\mathrm{KCl}$ (A.R., Sinopharm Chemical Reagent Co., Ltd, China) in equal molar ratio were mixed manually and dried at $473 \mathrm{~K}\left(200{ }^{\circ} \mathrm{C}\right)$ for 48 hours. The mixture was then placed into an alumina crucible (42 $\mathrm{mm}$ in inner diameter, $800 \mathrm{~mm}$ in height) in a vertical furnace as the electrolyte. The furnace was filled with flowing argon (99.99 pct) for 10 hours before heating.

Both polarization curves of the $\mathrm{TiC}$ anode and the graphite anode were measured in equimolar $\mathrm{KCl}-\mathrm{NaCl}$ by linear sweep voltammetry. The cyclic voltammograms of the molten salts after polarization were investigated with molybdenum wire as the working electrode. The $\mathrm{Ag} / \mathrm{AgCl}$ reference electrode was prepared by dipping $\mathrm{Ag}$ wire (1.5 $\mathrm{mm}$ in diameter) into a pre-dried 45 pet $\mathrm{NaCl}-45$ pct $\mathrm{KCl}-10$ pet $\mathrm{AgCl}$ (mol pct) mixture, which was held in an alumina tube with a slot and then heated to melt. ${ }^{[30]}$ Potentiostatic electrolysis was performed for the production of titanium in molten $\mathrm{NaCl}-\mathrm{KCl}$ with the one-time addition of $1 \mathrm{~mol}$ pet $\mathrm{TiCl}_{2}$ (99.98 pct, anhydrous, Sigma-Aldrich) at the potential of $-1.3 \mathrm{~V}$ between the cathode and anode. In the two-electrode cell, a steel plate (square in shape and $4 \mathrm{~cm}^{2}$ in area) served as the cathode electrode and $\mathrm{TiC}$ served as the anode. All experiments were performed at $1073 \mathrm{~K}\left(800{ }^{\circ} \mathrm{C}\right)$ for achieving the excellent fluidity for $\mathrm{NaCl}-\mathrm{KCl}$ melt under Ar atmosphere. The purpose of $\mathrm{TiCl}_{2}$ addition is to achieve a stable initial electrolysis current in the molten salt. The corresponding electrochemical measurement was conducted by Potentiostat/galvanostat model 273A \& Lock amplifier 5210. All electrodes were lifted out of the molten salt and naturally cooled in the furnace in an argon atmosphere after measurement. The detailed experimental setup is shown in Figure 1(a). The cathode deposit was washed by water and diluted $\mathrm{HCl}(0.05 \mathrm{M})$, and dried naturally for further structural characterization. X-ray diffraction patterns were collected to analyze the phase composition of the product with a Philips PW3040/60 diffractometer $(\mathrm{CuK} \alpha$ source, $\lambda=0.15406 \mathrm{~nm})$ at the rate of

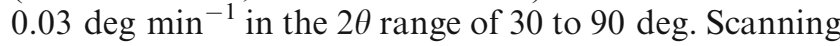
electron microscope (Shimadzu, SSX-550), operated at an acceleration voltage of $30 \mathrm{kV}$, was used to analyze the surface morphology of the deposit.

The polarization curve of $\mathrm{TiC}$ anode in the potential range between 0 and $2.0 \mathrm{~V}$ at $1073 \mathrm{~K}\left(800{ }^{\circ} \mathrm{C}\right)$ was studied by linear sweep voltammetry at the low sweep rate of $10 \mathrm{mV} \mathrm{s}^{-1}$ to investigate the electrochemical oxidation and dissociation of titanium from $\mathrm{TiC}$ anode and is shown in Figure 1(b). TiC lost electrons at the applied potential and dissolves in the molten salt in the form of titanium ions, which then moved to the cathode and were reduced there. Potential scan at the low rate led to oxidizing enough titanium and guaranteed apparent reduction/oxidation current peaks on subsequent cyclic voltammograms. In the current work, graphite was used to further study the electrochemical properties of the molten salt. The corresponding polarization curve is also presented in Figure 1(b). It can be observed that the current in the polarization curve of $\mathrm{TiC}$ anode shows a dramatic linear increase from $0.7 \mathrm{~V}$ with the increase in potential, which should correspond to the oxidation and dissociation of titanium from $\mathrm{TiC}$ anode because titanium can be electrochemically oxidized and dissociated from $\mathrm{TiC}$ anode before the decomposition of $\mathrm{NaCl}$ and $\mathrm{KCl}$ due to the low decomposition potential of $\mathrm{TiC}$ $\left(0.89 \mathrm{~V}\right.$ at $\left.1073 \mathrm{~K}\left(80{ }^{\circ} \mathrm{C}\right)^{[28]}\right)$ and its lower thermodynamic stability than $\mathrm{NaCl}$ and $\mathrm{KCl}$. The linear increase of the polarization current of $\mathrm{TiC}$ anode with an increasing potential also confirms that the oxidation and dissociation process of titanium from $\mathrm{TiC}$ is the rate-limited step. In the polarization curve of the graphite anode, the current is increased with the increase of potential from a high potential $(1.4 \mathrm{~V})$ corresponding to the evolution of chlorine on graphite anode.

In Figure 2, cyclic voltammograms of the molten salts on the molybdenum electrode were investigated in the potential range of 0 to $-2.5 \mathrm{~V}$ after the polarization experiments of both the $\mathrm{TiC}$ anode and the graphite anode. The sharp peak started from the potential of $-2.0 \mathrm{~V}$ in the cyclic voltammograms of the molten salt after polarization of the graphite anode is attributed to reduction of $\mathrm{Na}^{+}$and $\mathrm{K}^{+}$in the molten salt. The corresponding oxidation current peak in the reverse scan appeared at the potential of $-1.75 \mathrm{~V}$. No other reduction/oxidation current peak is observed in the cyclic voltammograms. The cyclic voltammograms of the molten salt after $\mathrm{TiC}$ anode polarization showed a couple of reduction/oxidation current peaks at the potential of -0.5 to $-0.7 \mathrm{~V}$, which are ascribed to the oxidation/reduction of $\mathrm{Ti}$ ions in the molten salt. This result is consistent with the results of the polarization curve and the thermodynamic analysis that $\mathrm{Na}^{+}$and $\mathrm{K}^{+}$in the molten salt have higher negative reduction potential than $\mathrm{Ti}$ ions. Investigation of cyclic voltammograms confirms that titanium is oxidized and dissociated from the soluble TiC anode in molten $\mathrm{NaCl}-\mathrm{KCl}$.

In addition, the results shown above further revealed that the reduction process of Ti ions in the molten salt to metallic $\mathrm{Ti}$ is a reversible one-step reaction and no other $\mathrm{Ti}$ ions in different valences were involved in the process. The following equation is used to determine the electron transfer number of $\mathrm{Ti}$ ions during the reduction process: ${ }^{[31]}$

$$
E_{\mathrm{p} / 2}=E_{1 / 2}+28 / n
$$

In Eq. [1], $E_{\mathrm{p} / 2}(\mathrm{mV})$ is the half peak potential, $E_{1 / 2}$ $(\mathrm{mV})$ the average value of potentials $E_{\mathrm{p}}$ (the peak potential in the cyclic voltammograms) and $E_{\mathrm{p} / 2}$, and $n$ is the electron transfer number. According to Eq. [1], $\mathrm{Ti}^{2+}$ was produced in molten $\mathrm{NaCl}-\mathrm{KCl}$ during polarization of the $\mathrm{TiC}$ anode:

$$
\mathrm{TiC} \leftrightarrow \mathrm{Ti}^{2+}+\mathrm{C}+2 \mathrm{e}^{-}
$$

The titanium deposition experiment was conducted in molten NaCl-KCl-1 mol pet $\mathrm{TiCl}_{2}$ for $10 \mathrm{~h}$ at a constant potential of $-1.3 \mathrm{~V}$ in a two-electrode cell with $\mathrm{TiC}$ as the anode and a steel plate as the cathode. The potential of $1.3 \mathrm{~V}$ over the cathodic peak potential of $0.9 \mathrm{~V}$ in the 


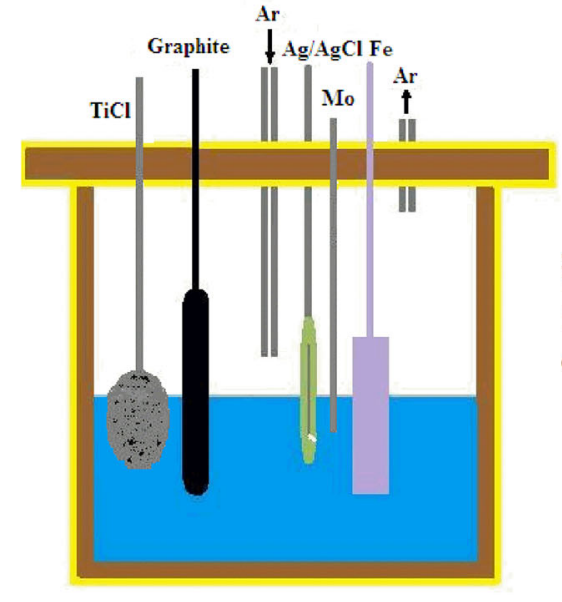

(a)

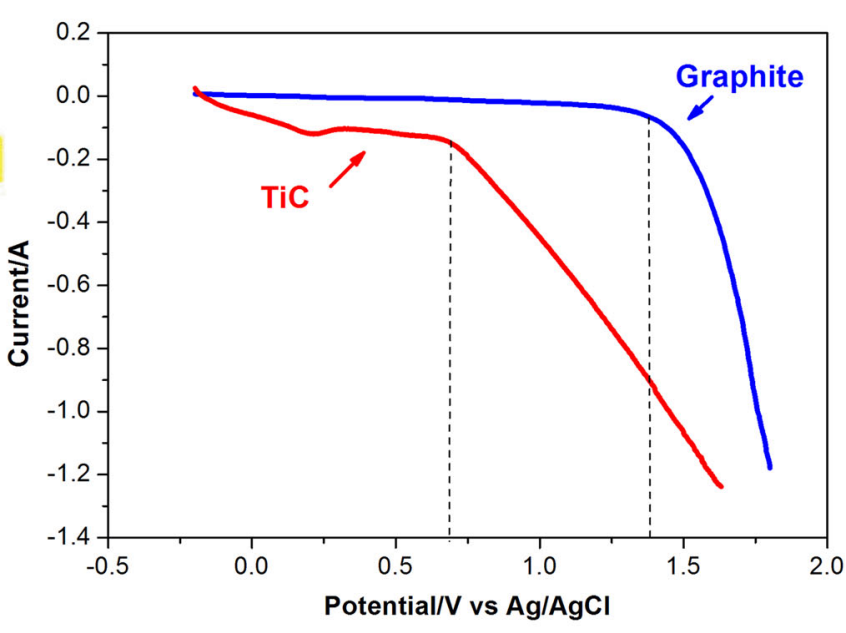

(b)

Fig. 1-(a) Experimental setup for the electrochemical characterization of molten salt; and $(b)$ polarization curves of graphite and TiC anode in molten $\mathrm{KCl}-\mathrm{NaCl}$ at $1073 \mathrm{~K}\left(800{ }^{\circ} \mathrm{C}\right)$.

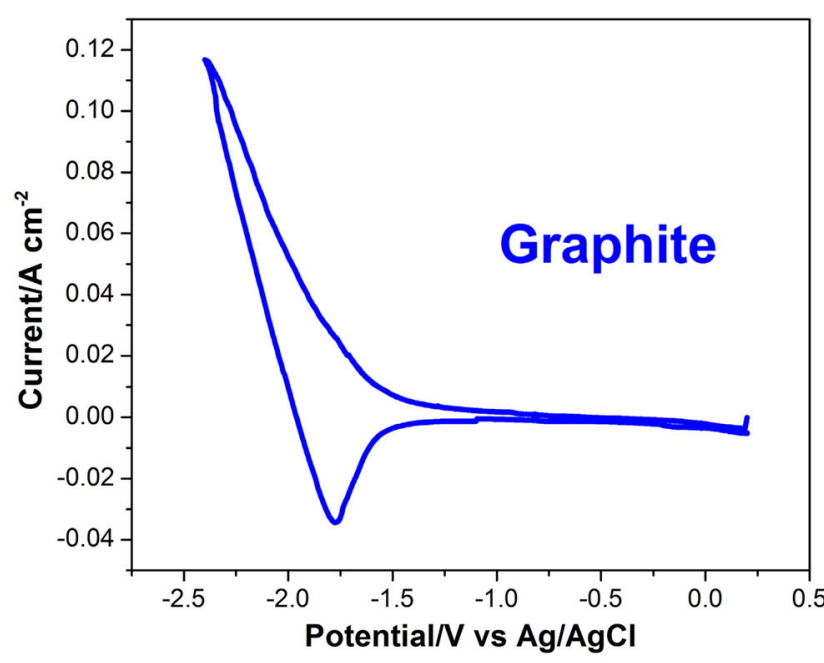

(a)

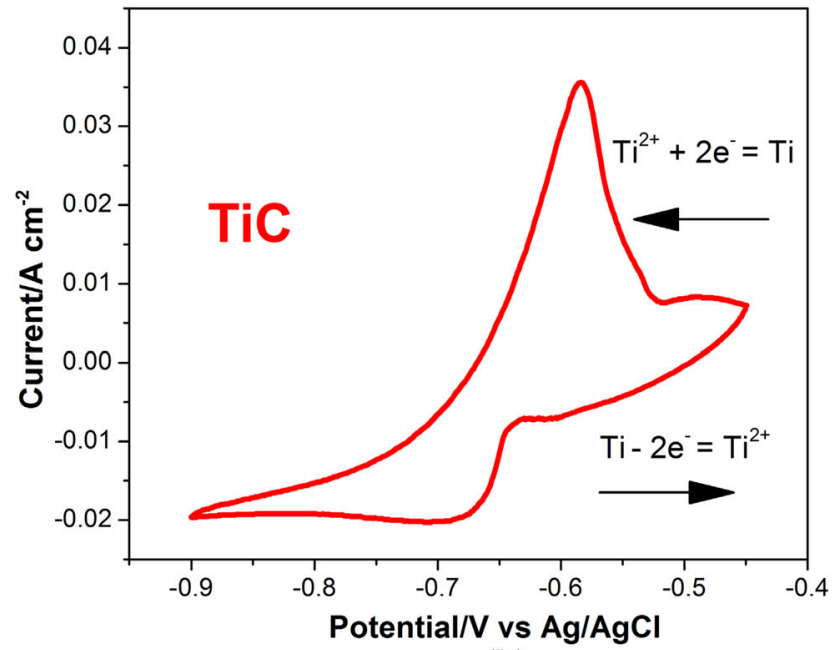

(b)

Fig. 2 - Cyclic voltammograms of the molten salts after polarization with the (a) graphite and $(b)$ TiC anode.

cyclic voltammogram (Figure 2(b)) was applied for achieving a high electrolysis rate. The initial $\mathrm{Ti}^{2+}$ concentration in the molten salt is necessary for achieving an apparent stable current during the electrolysis process. Since the theoretical decomposition potentials of $\mathrm{NaCl}$ and $\mathrm{KCl}$ are higher than $3.0 \mathrm{~V}$, no faradic current will be formed for the electrolysis in molten $\mathrm{NaCl}-\mathrm{KCl}$ at the potential of $1.3 \mathrm{~V}$. Titanium ion is dissociated from TiC anode by capturing electrons during the electrolytic process, while the initial current during the electrolyte process is required before the titanium ion moves and arrives at cathode. With the one-time addition of $1 \mathrm{~mol}$ pct $\mathrm{TiCl}_{2}$ in the molten salt, the reduction of $\mathrm{TiCl}_{2}$ to $\mathrm{Ti}$ metal on the cathode can maintain the initial electrolyte current. Figure 3 shows the time courses of current and potential for titanium electrolysis from molten NaCl-KCl-1 mol pct $\mathrm{TiCl}_{2}$ at

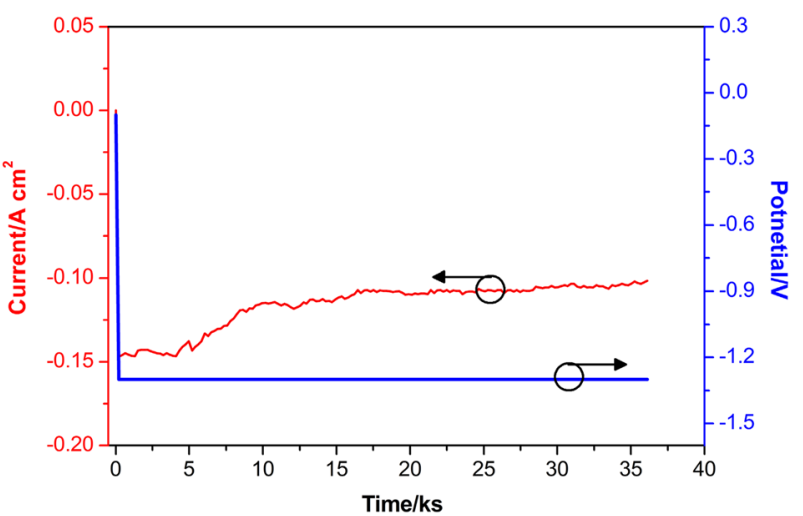

Fig. 3-The electrodeposition curve of titanium from molten $\mathrm{NaCl}-\mathrm{KCl}-1 \mathrm{~mol}$ pct $\mathrm{TiCl}_{2}$ at $1073 \mathrm{~K}\left(800^{\circ} \mathrm{C}\right)$ using the soluble $\mathrm{TiC}$ anode. 


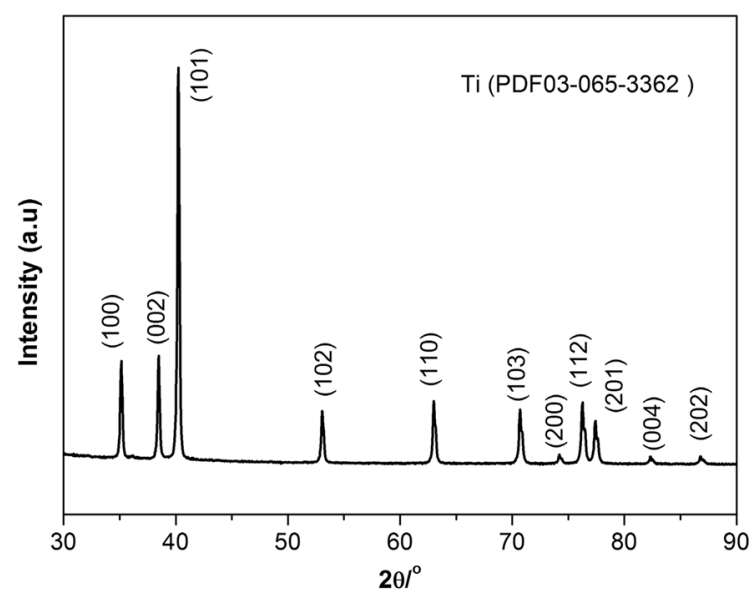

(a)

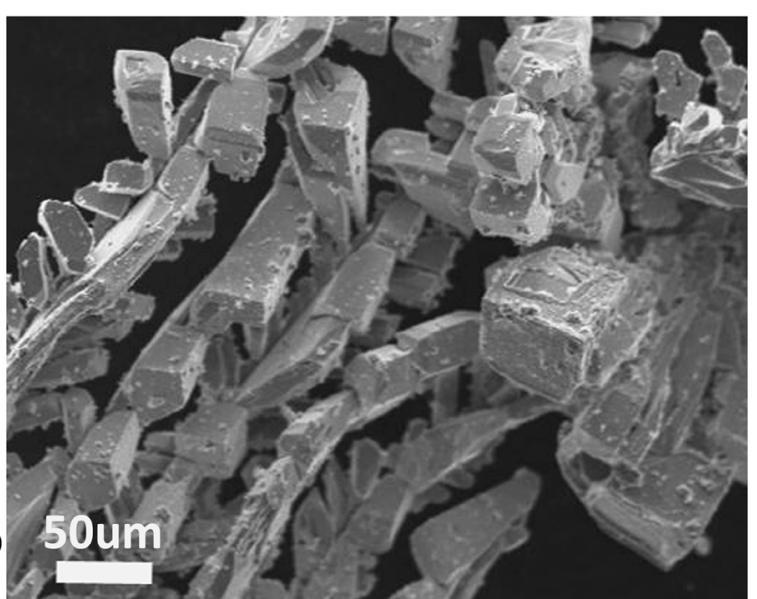

(b)

Fig. 4- (a) X-ray diffraction pattern and (b) SEM images of cathode deposit for investigation of its phase and surface morphology.

$1073 \mathrm{~K}\left(800{ }^{\circ} \mathrm{C}\right)$. It can be observed that the current fluctuated around $0.15 \mathrm{~A} \mathrm{~cm}^{-2}$ for $1.5 \mathrm{~h}$ and then decreased to about $0.10 \mathrm{~A} \mathrm{~cm}^{-2}$. The irregular surface of the sintered TiC anode can cause the current fluctuation. Meanwhile, the decrease in surface area of the $\mathrm{TiC}$ anode during the electrolysis process due to volume reduction arising from consumption of the soluble anode can also lead to the decrease of current. According to Faraday's law, the current efficiency of the electrolysis process is calculated and is 36.6 pct.

The deposit was then collected from the cathode substrate and cleaned ultrasonically in water and $\mathrm{HCl}$ $(0.05 \mathrm{M})$ for further structural characterization. Its phase composition was analyzed with XRD. The corresponding pattern is shown in Figure 4(a). It can be observed that all diffraction peaks are indexed as standard diffraction peaks of metallic $\alpha$-Ti (PDF 44-1294) with the space group of $P 63 / \mathrm{mmc}$. No secondary phase is observed in the product. It has been reported that the phase transfer temperature between $\alpha$-Ti to $\beta$-Ti occurs at around $1423 \mathrm{~K}\left(1150{ }^{\circ} \mathrm{C}\right) \cdot{ }^{[32]} \mathrm{All}$ experiments shown in the current work were performed at $1073 \mathrm{~K}\left(800{ }^{\circ} \mathrm{C}\right)$, and $\alpha$-Ti was detected as the sole Ti phase. The sharp peaks at 40.23 and $38.48 \mathrm{deg}$, which are related to (101) and (002) planes in the hcp crystal structure of $\mathrm{Ti}$, were used to calculate the grain size and the lattice parameter of the deposited $\alpha$-Ti. According to Scherrer's equation, the grain size value of the produced titanium was measured to be $44 \mathrm{~nm}$. The lattice parameters of $\alpha$-Ti based on the strongest (101) peak were estimated to be $a=0.2956 \mathrm{~nm}, c=0.4684 \mathrm{~nm}$. These values are consistent with the previous report. ${ }^{[33]}$ The XRD results confirm the successful extraction of titanium with high crystallinity by molten salt electrolysis of the $\mathrm{TiC}$ anode in $\mathrm{NaCl}-\mathrm{KCl}-1 \mathrm{~mol}$ pet $\mathrm{TiCl}_{2}$. In Figure 4(b), the surface morphology of deposited titanium is analyzed by SEM. It should be noted that dendritic titanium has formed, which may be attributed to the high current density in the electrolysis process. As reported by Bouchet, ${ }^{[34]}$ growth of dendritic metal is found in lithium ion batteries with a large concentration gradient of ions in the electrolyte solution. Dendritic titanium was also produced in Takeuchi and Watanabe's work in case of large current density. ${ }^{[21]}$ In the current experiment, the relatively high current density of electrolysis likely leads to the high concentration gradient of Ti ions during electrolysis, which results in the inhomogeneous growth of titanium in different directions and thus formation of the dendritic crystal. However, the detailed formation mechanism of dendritic titanium is still unknown and requires further study.

To conclude, both the polarization curve and cyclic voltammograms show that titanium can be oxidized and dissociated from the $\mathrm{TiC}$ anode and dissolved into molten $\mathrm{NaCl}-\mathrm{KCl}$ in the form of $\mathrm{Ti}^{2+}$. The reduction/ oxidation of $\mathrm{Ti}^{2+} / \mathrm{Ti}$ in the molten salt is a one-step reaction. Titanium with high crystallinity was extracted successfully by molten salt electrolysis using the soluble $\mathrm{TiC}$ anode. Dendritic titanium with no impurities was obtained by potentiostatic electrolysis in molten $\mathrm{NaCl}-\mathrm{KCl}-1$ mol pct $\mathrm{TiCl}_{2}$. The current work advanced the understanding on the process of electrochemical oxidation and dissociation of titanium from the soluble $\mathrm{TiC}$ anode and reduction process of titanium ions in molten $\mathrm{NaCl}-\mathrm{KCl}$, and provided guidance for further investigation on titanium extraction by the molten salt electrolysis method.

\section{ACKNOWLEDGMENTS}

This work was supported by the National Natural Science Foundation of China Nos. 51274058, 51574062.

\section{REFERENCES}

1. C. Yeh, H. Wang, and W. Chen: J. Alloys Compd., 2008, vol. 450, pp. 200-07.

2. D. Wever, A. Veldhuizen, M. Sanders, J. Schakenraad, and J. Van Horn: Biomaterials, 1997, vol. 18, pp. 1115-20.

3. R. Boyer: Mater. Sci. Eng., A, 1996, vol. 213, pp. 103-14. 
4. W. Kroll: Trans. Electrochem. Soc., 1940, vol. 78, pp. 35-47.

5. G.Z. Chen, D.J. Fray, and T.W. Farthing: Nature, 2000, vol. 407, pp. 361-64.

6. D.J. Fray: JOM, 2001, vol. 53, pp. 27-31.

7. G.Z. Chen and D.J. Fray: J. Electrochem. Soc., 2002, vol. 149, pp. E455-67.

8. S. Wang and Y. Li: J. Electroanal. Chem., 2004, vol. 571, pp. $37-$ 42.

9. M. Ma, D. Wang, W. Wang, X. Hu, X. Jin, and G.Z. Chen: J. Alloys Compd., 2006, vol. 420, pp. 37-45.

10. R.L. Centeno-Sánchez, D.J. Fray, and G.Z. Chen: J. Mater. Sci, 2007, vol. 42, pp. 7494-501.

11. P.K. Tripathy, M. Gauthier, and D.J. Fray: Metall. Mater. Trans. B, 2007, vol. 38B, pp. 893-900.

12. E. Gordo, G.Z. Chen, and D.J. Fray: Electrochim. Acta, 2004, vol. 49, pp. 2195-208.

13. K. Mohandas and D. Fray: Metall. Mater. Trans. B, 2009, vol. 40B, pp. 685-99.

14. X. Zou, X. Lu, Z. Zhou, W. Xiao, Q. Zhong, C. Li, and W. Ding: J. Mater. Chem. A, 2014, vol. 2, pp. 7421-30.

15. D. Tang, W. Xiao, L. Tian, and D. Wang: J. Electrochem. Soc., 2013, vol. 160, pp. F1192-96.

16. K. Ono and R.O. Suzuki: JOM, 2002, vol. 54, pp. 59-61.

17. T. Okabe, M. Nakamura, T. Oishi, and K. Ono: Metall. Trans. B, 1993, vol. 24B, pp. 449-55.

18. D.R. Sadoway: JOM, 1991, vol. 43, pp. 15-19.

19. S. Jiao and H. Zhu: J. Mater. Res., 2006, vol. 21, pp. 2172-75.
20. S. Jiao and H. Zhu: J. Alloys Compd., 2007, vol. 438, pp. 243-46.

21. S. Takeuchi and O. Watanabe: J. Jpn. Inst. Met., 1964, vol. 28, pp. 627-32.

22. Y. Hashimoto: J. Jpn. Inst. Met., 1968, vol. 32, pp. 1327-34.

23. G. Haarberg, T. Støre, and R. Tunold: Electrochim. Acta, 2012, vol. 76, pp. 256-61.

24. S. Wang, G.M. Haarberg, and E. Kvalheim: J. Iron. Steel Res. Int., 2008, vol. 15, pp. 48-51.

25. Y. Castrillejo, A.M. Martínez, R. Pardo, and G.M. Haarberg: Electrochim. Acta, 1997, vol. 42, pp. 1869-76.

26. A. Martınez, B. Børresen, G. Haarberg, Y. Castrillejo, and R. Tunold: J. Electrochem. Soc., 2004, vol. 151, pp. C508-13.

27. H.-L. Li, Z.-N. Du, G.-L. Wang, and Y.-C. Zhang: Mater. Lett., 2010, vol. 64, pp. 431-34.

28. Y.J. Liang and Y.C. Che: Handbook of Inorganic Thermodynamic Data, NEU Press, Shenyang, 1993, p. 56.

29. L.E. Hollander, Jr: J. Appl. Phys., 1961, vol. 32, pp. 996-97.

30. P. Gao, X. Jin, D. Wang, X. Hu, and G.Z. Chen: J. Electroanal. Chem., 2005, vol. 579, pp. 321-28

31. Q.X. Zha: Introduction to Kinetics of Electrode Processes, Science Press, Beijing, 2002.

32. J.-C. Gachon, A. Rogachev, H. Grigoryan, E. Illarionova, J.-J. Kuntz, D.Y. Kovalev, A. Nosyrev, N. Sachkova, and P. Tsygankov: Acta Mater., 2005, vol. 53, pp. 1225-31.

33. D.V. Louzguine-Luzgin, L.V. Louzguina-Luzgina, H. Kato, and A. Inoue: Acta Mater., 2005, vol. 53, pp. 2009-17.

34. R. Bouchet: Nat. Nanotechnol., 2014, vol. 9, pp. 572-73. 